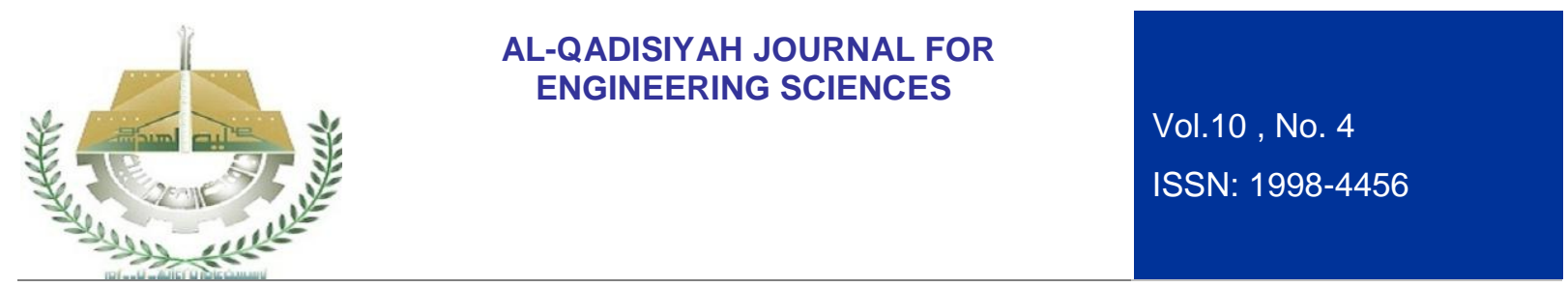

\title{
STUDY OF USING THE CRUSHED CLAY BRICKS WITH NATURAL AGGREGATE AS UNBOUND SUBBASE PAVEMENT LAYER IN SEGREGATED FORM
}

\author{
Lecturer, Dr. Ali Abdulla Abed, \\ University of Al-Qadisiyah, College of Engineering, Civil Engineering Department. \\ E-mail: Ali.Abed@qu.edu.iq
}

Assist. Lecturer, Mr. Zaid Abdul Zahra Mahdi,

University of Al-Qadisiyah, College of Engineering, Roads and Transportation Engineering Department.

E-mail: Zaid.Mahdi@qu.edu.iq

Received on 7 August 2017 Accepted on 31 October 2017 Published on 15 January 2018

DOI: 10.30772/qjes.v10i4.497

\begin{abstract}
Construction and demolition of buildings and structures are producing excess or waste material which is including concrete, brick, steel, etc. Conservation and reuse of resources is a necessity in achieving sustainability across the globe, crushed brick could be safely added to crush rock blends in pavement sub-base applications with percent up to $25 \%$. The experimental work was consisted of two groups of samples depending on percent volume of each material, each group samples have 6 different layering blends patterns prepared by spreading the pure materials in layers (segregated form) of Crushed Bricks Sand (CBS) and Natural Aggregate (NA), in addition to the two control samples and then experimentally tested to compare with the requirements of Iraqi specification for roads and bridges. The experimental work was consisted of Atterberg limits, sieve analysis, moisture-density relationship and California Bearing Ratio (CBR) tests. The results show that using of the crushed bricks as sand with natural aggregate as unbound subbase in segregated form is feasible and agreed with the Iraqi specification requirements because the CBR of CBS was improved when blended with the NA at all the patterns, the best pattern is that which containing three layers NA and two CBS $160 \%$ NA and $40 \%$ CBS by volume) and the NA was at the top, then CBS in alternated sequence that improves the CBR value to 1.6 times compared with NA control or 8 times of CBS control because the sporadic distribution reduces the effect of the low bearing material, in another words; collect the layers of the same material doesn't give best improvement.
\end{abstract}

Keywords: Crushed Clay Bricks (CB), Crushed Bricks Sand (CBS), Natural Aggregate (NA), Unbound Subbase, segregated layers, California Bearing Ratio (CBR).

\section{INTRODUCTION AND LITERATURE REVIEW}

Construction and demolition of buildings and structures are producing excess or waste material which is including concrete, brick, steel, and other building materials and products [1], the recycling and reuse of 


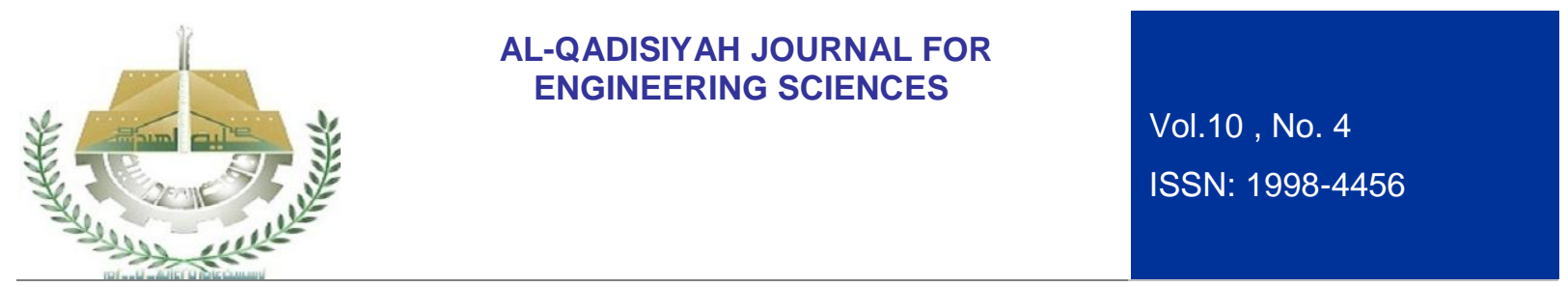

industrial wastes should be considered in geotechnical and pavement applications in order to generate sustainable solutions [2], [3]. The replacement of traditional gravel materials with alternative materials is increasingly preferred from both environmental and economic perspectives [4].

Crushed clay bricks and roof tiles are among the best aggregates, for use in concrete are known have to resistance at high temperatures, and concrete with such aggregates performs much better than similar concretes containing granite aggregate [5].

Limited researchers had investigated on the possibility of using crushed clay bricks as aggregates in unbound subbase materials applications and they included that is feasible for using in subbase applications. Those researchers like: Zakaria and Rauf reported that, good quality brick aggregate in unbound condition has found to be satisfactory from strength consideration [6], Poon and Chan show that the replacement of recycled concrete aggregates by crushed clay brick further increased the optimum moisture content and decreased the maximum dry density and when the coarse crushed clay brick content increased. They show causes of that to the lower particle density and higher water absorption of crushed clay brick compared to those of recycled concrete aggregates, the subbase using crushed clay brick as the fine aggregate was less susceptible to moisture variations when compared to the subbase using recycled concrete aggregate as the fine aggregate. The use of crushed clay brick lowered the CBR value. A 4-day soaked period had a negligible influence on the CBR values of the recycled subbase [7], it was feasible to blend recycled concrete aggregate and crushed clay brick to produce a subbase with a soaked CBR value of at least $30 \%$. Aatheesan et al., found that crushed brick could be safely added to crushed rock (class 3 ) potentially up to $30 \%$ [2], and could be safely added to recycle concrete aggregate and crushed rock blends with percent up to $25 \%$ [8]. Arulrajah et al., concluded that crushed brick may have to be blended with other durable aggregates to improve its durability and to enhance its performance in pavement sub-base [9].

Arulrajah et al. (2013), evaluated the geotechnical and geo-environmental properties of five types of Construction and Demolition materials "Recycled Concrete Aggregate (RCA), Crushed Brick (CB), Waste Rock (WR), Reclaimed Asphalt Pavement (RAP) and Fine Recycled Glass (FRG)", they mentioned that "there is ability to improve the behavior of CB, RAP and FRG materials to enable their usage in pavement sub-bases by additives or mixed in blends with high quality aggregates", they find that limited work has been conducted on using crushed brick in geotechnical applications although there are several research works focusing on using CB in concrete mixture, concrete tiles and blocks [10].

The geotechnical properties of recycled CB had showed in some researches, like in Arulrajah et al., and from their study on CB from the recycling site (typically may consists of up to $30 \%$ other materials) with a maximum particle size of $20 \mathrm{~mm}$, found that the fine content \% (6.6), CBR \% (123-138), compaction modified density $\left(19.82 \mathrm{kn} / \mathrm{m}^{3}\right.$ ) with optimum moisture \% (10.7), and Tri-axial test (CD) Cohesion (41.1kPa) [9]. And Mithaq Albeer Louis, et al., in their research worked on CB sand with the classification according to (USCS) was poorly graded sand (SP) and it is not plastic matter [11]. Also Arulrajah et al in their research, RCA, CB and WR in particular are found to also meet the physical and shear strength requirements for aggregates in pavement base/subbase applications [12]. In addition to Wijewardana et al had found the 100\% recycled brick sample achieved a maximum dry density of $2020 \mathrm{~kg} / \mathrm{m} 3$ and a CBR value of $113 \%$. The blend of $50 \%$ crushed bricks and $50 \%$ gravel also satisfied the Atterberg limit dry density $\left(1779 \mathrm{~kg} / \mathrm{m}^{3}\right)$ and CBR value (32\%) [4]. And Diagne et al., in their research results indicated that Los Angles Abrasion of 100\% recycled clay bricks and $100 \%$ Recycled concrete aggregate were $36.8 \%$ and $29.9 \%$, respectively [13].

Other studies on CB with stabilizers were found to be viable for usage as pavement base/subbase construction materials. These studies like in Mithaq Albeer Louis, et al. when studied Blend the (RAP) with CB sand and stabilized with cement and/or lime, concluded that increasing bricks sand increase the compression strength [11]. And Mohammadinia et al in their research on using the Fly ash to stabilize (CB) and (RAP), the results of geotechnical investigation showed a considerable increase in MR and unconfined compressive strength of CB and RAP [14].

This paper describes the technical feasibility on application of the crushed clay bricks as fine aggregate (sand) in road construction in segregated form with natural aggregate. This investigation involved making samples with laying the Natural Aggregate (NA) and Crushed Bricks Sand (CBS) sequentially and comparing the CBR results with the pure Natural Aggregate, in light of the economic and environment 


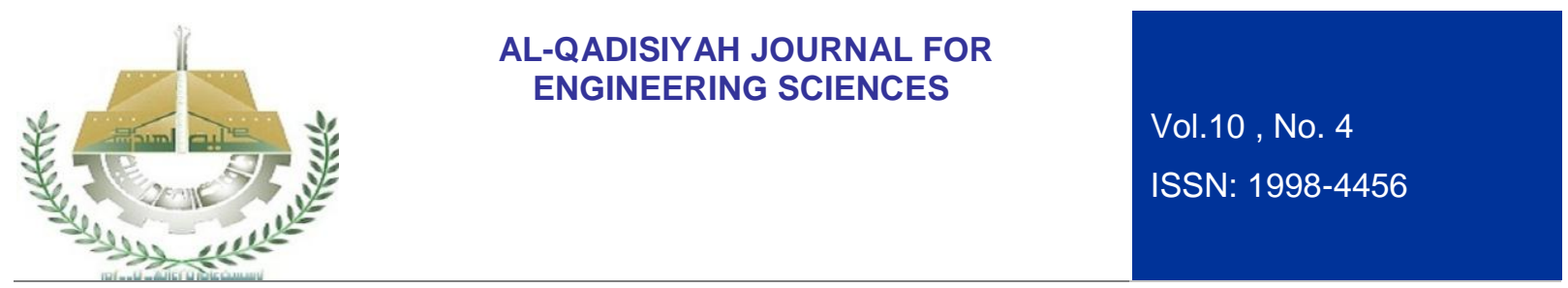

objectives, this paper aims to use the (CBS) with easy method of construction to reduce waste material and conserve the natural one.

\section{METHODOLOGY}

The experimental work was consisted of two stages:

First stage: the control blends samples were prepared to study the geotechnical properties of NA and the CBS each separately for a comparison later, figures (1 and 2 ) show the materials.

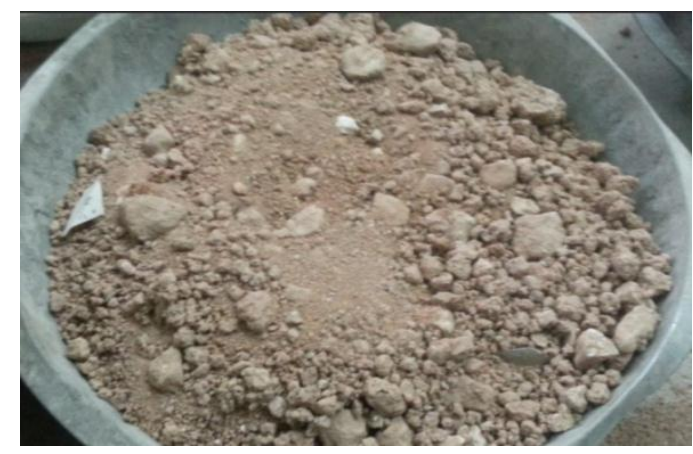

a. the natural aggregate sample.

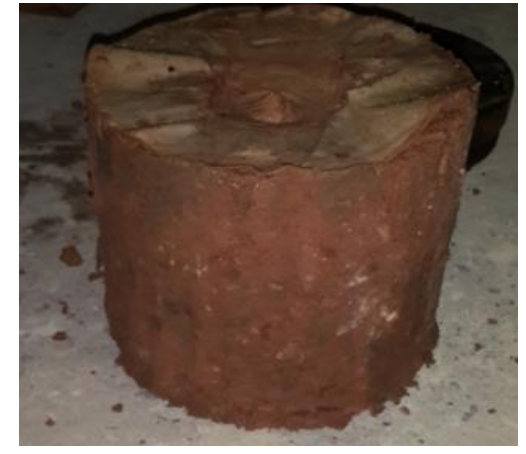

b. the molded sample.

Figure 1: the natural aggregate material.

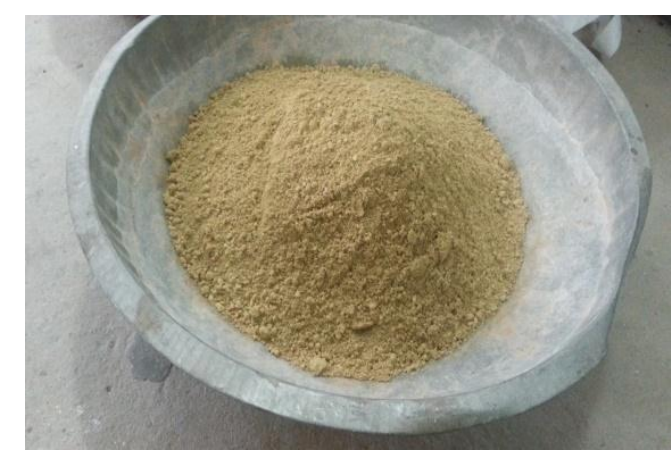

a. crushed bricks sand sample.

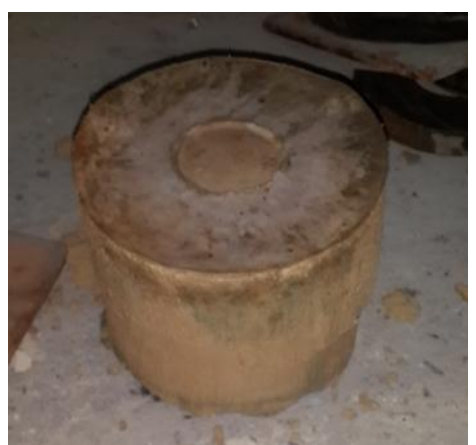

b. molded sample.

Figure 2: the crushed bricks sand material.

Second stage: two groups of layering blends were prepared by spreading the the pure materials in layers, group (A) composed of (60\% NA and $40 \%$ CBS by volume), group (B) ( $60 \%$ CBS and $40 \%$ NA by volume), different blends patterns of CBS with NA were prepared for each group as shown in table (1) and figure (3), then the samples was experimentally tested to compare with the requirement of Iraqi general specifications for roads and bridges.

Table 1: illustrates the experimental work blends patterns.

\begin{tabular}{|c|c|c|c|c|c|c|c|c|c|c|c|c|}
\hline \multirow{2}{*}{$\begin{array}{c}\text { Layer no. } \\
\text { (from top) }\end{array}$} & \multicolumn{5}{|c|}{ Blends patterns of Group (A) } & \multicolumn{5}{|c|}{ Blends patterns of Group (B) } \\
\cline { 2 - 14 } & A1 & A2 & A3 & A4 & A5 & A6 & B1 & B2 & B3 & B4 & B5 & B6 \\
\hline 1 & NA & NA & NA & NA & NA & CBS & CBS & NA & CBS & CBS & CBS & CBS \\
\hline 2 & CBS & CBS & NA & NA & NA & NA & NA & CBS & CBS & CBS & NA & CBS \\
\hline 3 & NA & CBS & CBS & CBS & NA & NA & CBS & CBS & NA & CBS & CBS & NA \\
\hline
\end{tabular}




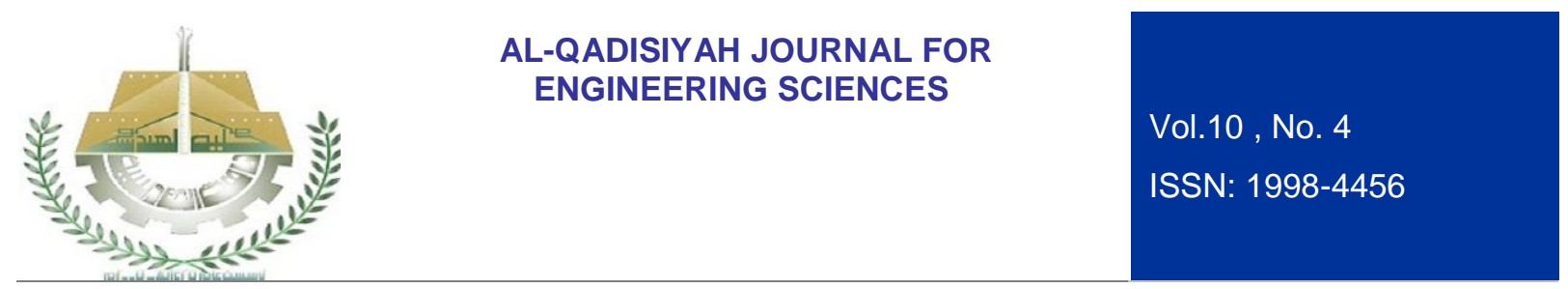

\begin{tabular}{|c|c|c|c|c|c|c|c|c|c|c|c|c|}
\hline 4 & CBS & NA & CBS & NA & CBS & NA & NA & CBS & NA & NA & CBS & NA \\
\hline 5 & NA & NA & NA & CBS & CBS & CBS & CBS & NA & CBS & NA & NA & CBS \\
\hline
\end{tabular}

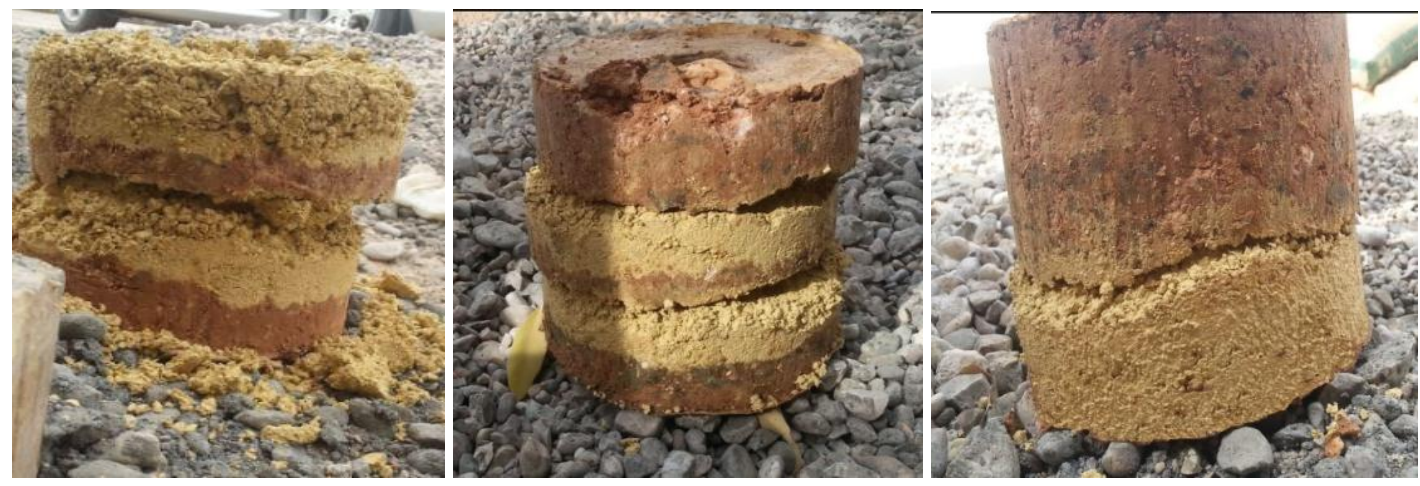

Figure 3: samples of blends patterns.

To evaluate these types and to find the geotechnical properties, the tests below was achieved:

1. Grain size distribution analysis according to ASTM C 136 [15].

2. Liquid and plastic limits according to ASTM D 4318 [16].

3. Specific Gravity and Absorption for Fine Aggregate according to ASTM C 128 [17].

4. Moisture - Density Relations according to ASTM D 1557 using modified proctor method [18].

5. California Bearing Ratio (CBR\%) according to ASTM D 1883 [19].

\section{MATERIALS}

\subsection{NATURAL AGGREGATE (NA):}

The Natural Aggregate was the ordinary subbase material used in the middle and southern region of Iraq from Al-Najaf city quarries, graded as middle limits of subbase course type $C$ as specified according to the Iraqi general specifications for roads and bridges (SCRB/ R6. 2007) [20] as shown in table (2). The Plastic and Liquid Limits are $18.5 \%$ and $23.7 \%$ respectively, the Plasticity Index was 5.2 and the Maximum Dry Density M.D.D was $2.1 \mathrm{gm} / \mathrm{cm} 3$ with O.M.C 9.6\%. The good gradation and presence of coarse aggregate lead to raise CBR, it was $45 \%$ at M.D.D. This result agreed with the Iraqi requirements for subbase materials. The high percent of fines with high plasticity make good bonds but the displacement increase when loading.

Table 2: grade requirements - selected granular material (SCRB. 2007/ R6).

\begin{tabular}{|c|c|c|c|c|c|c|}
\hline \multirow{4}{*}{$\begin{array}{c}\text { Sieve size } \\
(\mathrm{mm})\end{array}$} & \multicolumn{5}{|c|}{ Percent of passing } \\
\cline { 2 - 7 } & Type A & Type B & Type C & Type D & Natural aggregate \\
\cline { 2 - 7 } & 75 & 100 & - & - & - & - \\
\cline { 2 - 7 } & 50 & $100-95$ & 100 & - & - & - \\
\cline { 2 - 7 } & 25 & - & $95-75$ & 100 & 100 & 100 \\
\cline { 2 - 7 } & 9 & $65-30$ & $75-40$ & $85-50$ & $100-60$ & 67.5 \\
\cline { 2 - 7 } & 4.75 & $55-25$ & $60-30$ & $65-35$ & $85-50$ & 50 \\
\cline { 2 - 7 } & 2.36 & $42-16$ & $47-21$ & $52-26$ & $72-42$ & 39 \\
\cline { 2 - 7 } & 0.3 & $18-7$ & $28-14$ & $28-14$ & $42-23$ & 21 \\
\hline
\end{tabular}




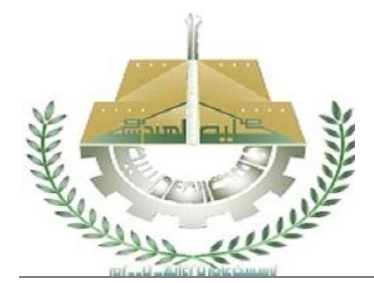

AL-QADISIYAH JOURNAL FOR ENGINEERING SCIENCES

Vol. 10 , No. 4

ISSN: $1998-4456$

\begin{tabular}{|c|c|c|c|c|c|}
\hline 0.075 & 8-2 & $15-5$ & $15-5$ & $20-5$ & 10 \\
\hline CBR \% (minimum) & 45 & 35 & 30 & 20 & \\
\hline
\end{tabular}

\subsection{CRUSHED BRICKS SAND (CBS):}

The crushed bricks sand brought from waste clay bricks then crushed to pass from sieve $9.5 \mathrm{~mm}$. Figure (4) show the grain size. It's classification according to the Unified Soil Classification System as well graded sand (SW) and the Group Index (0). It's classification according to AASHTO method as A-3. Using of the crushed clay brick as the fine aggregate (sand) was low susceptible to moisture variations as shown in figure (5) that's also mentioned in Poon and Chan (2006) [7], it have the higher optimum moisture content due to the lower density and higher water absorption, this make the CBS feasible using in layer exposed to moisture like in subbase. The properties of CBS shown in table (3), CBR value was lower whan it's value in NA due to the gradation of CBS as sand (without coarse aggragte) and be not cohesive non-plastic material and became loose (without bonds) under moisture. The CBR value is high as compared with the origin materials of bricks (sand, clay, and silt), becuase its firing to $1000{ }^{\circ} \mathrm{C}$ and dehydration and fusion process make it turns into a dense glass material to produce cohesion and hardness [21], the firing process is containing oxidations of $\mathrm{CaCO}_{3}, \mathrm{MgCO}_{3}$ and $\mathrm{Fe}_{2} \mathrm{O}_{3}$ also changes in chemical composition like in kaolin $\left(2 \mathrm{SiO}_{2} \cdot \mathrm{Al}_{2} \mathrm{O}_{3} \cdot 2 \mathrm{H}_{2} \mathrm{O}\right)$ to $\mathrm{SiO}_{2}$ and $\mathrm{Al}_{2} \mathrm{O}_{3}$ then to produce new composition. The chemical composition of bricks $\mathrm{Al}_{2} \mathrm{Si}_{2} \mathrm{O}_{5}\left(\mathrm{OH}_{4}\right), \mathrm{SiO}_{2}$ plus fine stones [22], the presence of alumina in raw materials of bricks give it the strength [23]. In light of the Iraqi specifications requirements; the CBR value doesn't agreed with the limit of the subbase course when used alone.

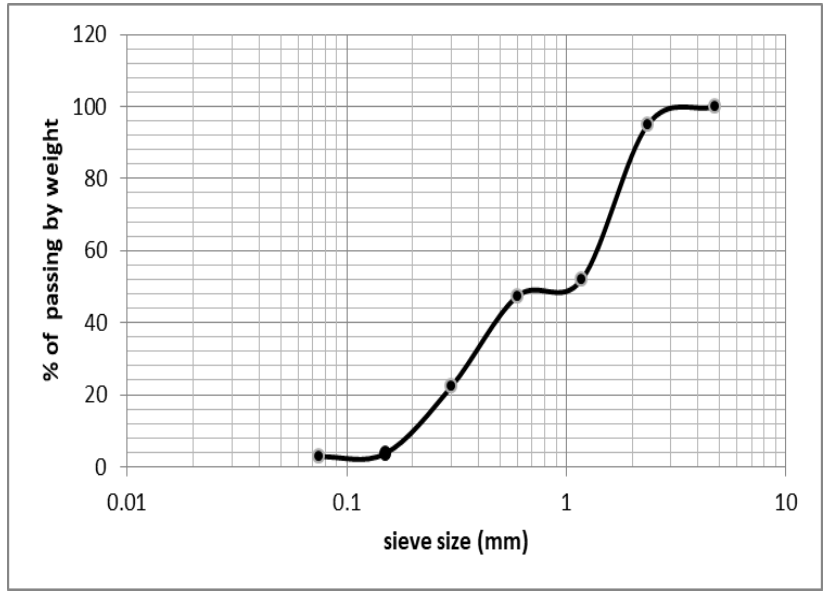

Figure 4: illustrates the grain size distribution of crushed bricks sand.

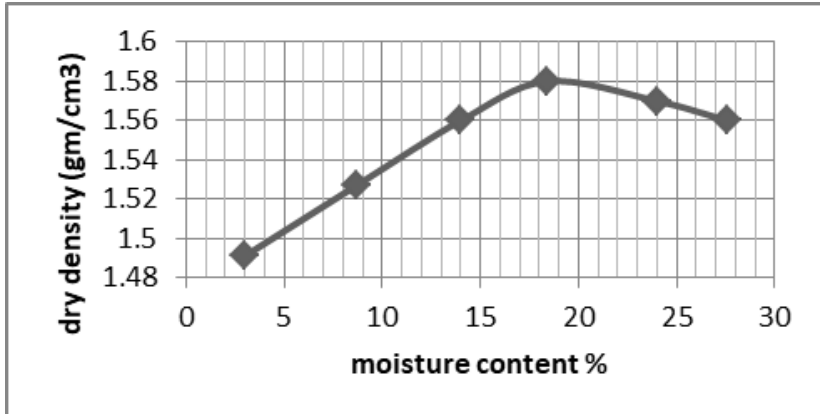

Figure 5: the moisture-density relationship of crushed bricks sand. 


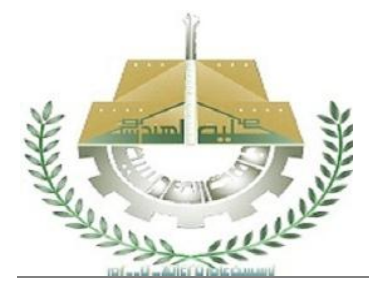

Table 3: illustrates the properties of tested crushed bricks sand.

\begin{tabular}{|c|c|c|c|c|c|c|}
\hline $\begin{array}{c}\text { Fines } \\
\text { content }\end{array}$ & $\begin{array}{c}\text { M.D.D } \\
\mathrm{Gm} / \mathrm{cm}^{3}\end{array}$ & $\begin{array}{c}\text { O.M.C } \\
\%\end{array}$ & $\begin{array}{c}\text { CBR } \\
\%\end{array}$ & $\begin{array}{c}\text { Plastic limit } \\
\text { P.L \% }\end{array}$ & $\begin{array}{c}\text { Apparent specific } \\
\text { gravity }\end{array}$ & $\begin{array}{c}\text { Water } \\
\text { absorption \% }\end{array}$ \\
\hline $1.6 \%$ & 1.58 & 20 & 9 & NP & 2.86 & 6.3 \\
\hline
\end{tabular}

\section{RESULTS AND DISCUSSION}

\subsection{FOR BLEND PATTERNS OF GROUP (A):}

As shown in figure (6), the CBS bearing ratio was improved and the whole CBR results within the requirements of the Iraqi specifications for subbase type $C$. The CBR values were decreased from $72 \%$ (at pattern A1) to $30 \%$ at pattern A6 Because of the collection of two or more adjacent layers of the same material, the characteristics of that substance will be shown. In contrast, when spreading the pure materials in alternated form layers consecutive NA then CBS, this will show the best results. So the best pattern was A1 which also because the NA at top which has the higher bearing ratio (due to presence of the coarse aggregate and fines bonding) covered the CBS layers (which was the loose and weak material), and the minimum thickness of the CBS made the load transmitted to the below NA layer which carried and supported, when compared bearing results of this pattern with the control blends, it is higher than the NA sample (by 1.6 times) and CBS (by 8 times), the sand works as leveling and reparation gradation the segregated particles from the previous spread layer also it is reducing the vertical displacement of the pattern due to its non-plasticity property in it's fines, and also CBS has higher CBR than ordinary soils fines with less susceptibility to moisture. The CBS at top layer reduced the bearing ratio due to it's charecteristics of not cohesive non-plastic material and loose (without bonds) and the less bearing without covering as shown in pattern $A 6$, this $C B R$ value was the least among all the patterns results not just due to presence of the low bearing (CBS) layer at top, but CBS didn't be between the NA layers to improve the NA layers by reducing the displacement, also lower than the control NA sample, this CBR was improved for subbase layer to 3.3 times as compared with the CBS control sample.

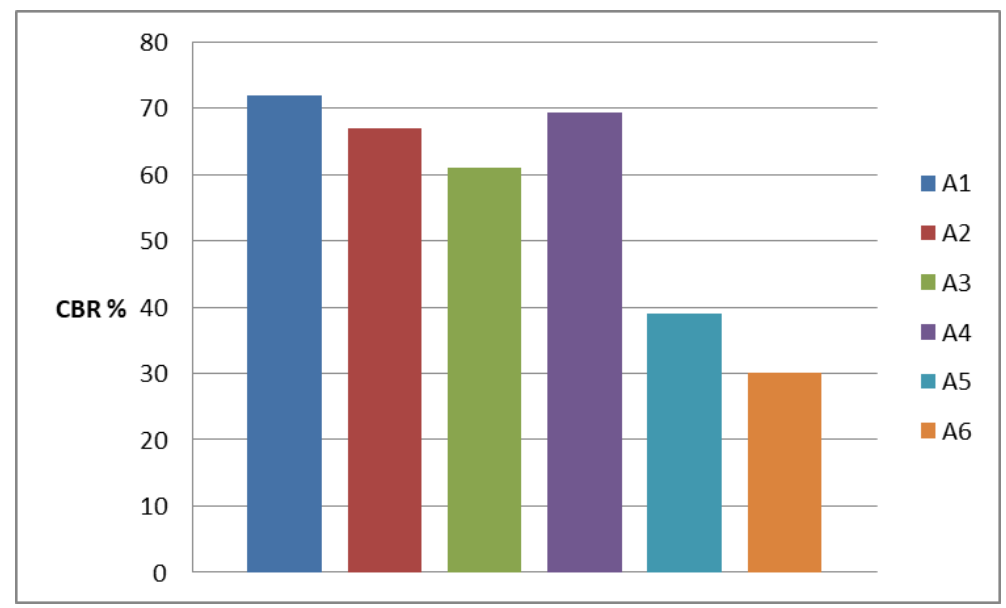

Figure 6: the CBR\% test results of group $(A)$ blends patterns.

\subsection{FOR BLEND PATTERNS OF GROUP (B):}

As shown in figure (7), the CBS bearing ratio was improved and the whole CBR results within the requirements of the Iraqi specifications for subbase type $C$ except samples $B 4$ and $B 6$ they are within the type $D$, the CBR values were less than those in group $(A)$ due to the high percent of low bearing material (CBS) opposing NA in spite of reducing the vertical displacement. The best CBR result was $45 \%$ at pattern B1 then began to degrease to $26 \%$ because of collecting two layers or more of same material especially the NA (due to displacement). Also, the low values due to existence the CBS at top layer (loose, low bearing 


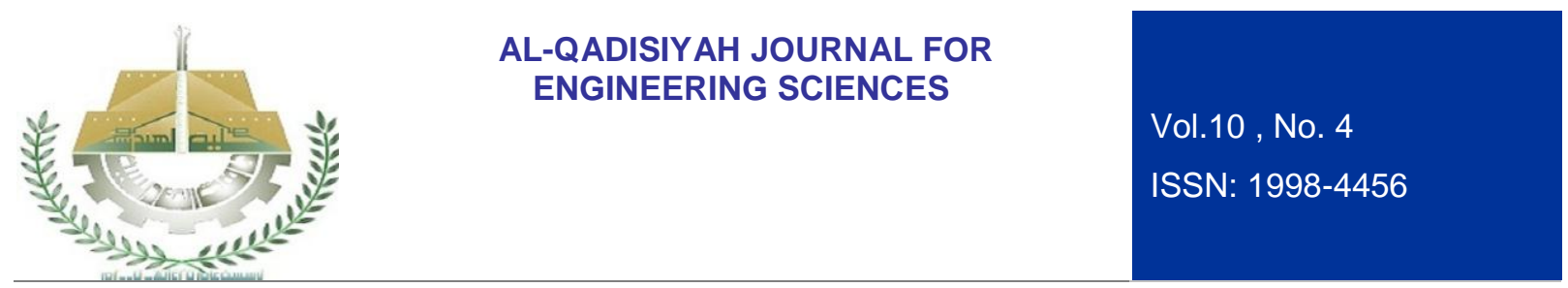

material and it's grade as fine aggregate). The next best pattern was the B2 because the top layer was NA which covered CBS. Although the pattern B1 consists of just $40 \%$ NA with $60 \%$ CBS, it gave the same CBR $\%$ value of control NA sample because of reducing the displacement. And when compare it with CBS control blend, the CBR was improved to five times because the NA improve the CBS. This pattern test result satisfied the Iraqi requirements for subbase course depending on CBR (it is comply with type A). The CBR result of pattern $\mathrm{B} 2$ was $34.7 \%$ at 0.1 inch penetration and decreased at 0.2 inch to be $25 \%$ because the load had transmitted to the under layers which was lower bearing and high thickness of CBS allthough the top layer was the NA. This CBR value is larger than it's in pattern A6 in spite of increasing the CBS because the NA at top carry loads more than CBS. Although this pattern has the same percent of CBS like in pattern $\mathrm{B} 1$ but the CBR is less due to thickness layer of CBS (collected). Also, this CBR result is lower than the control NA sample due to presence and thickness of the low bearing CBS without spreads the NA between them. The CBR of B2 was improved for subbase layer to 3.7 times as compare it with CBS control sample.

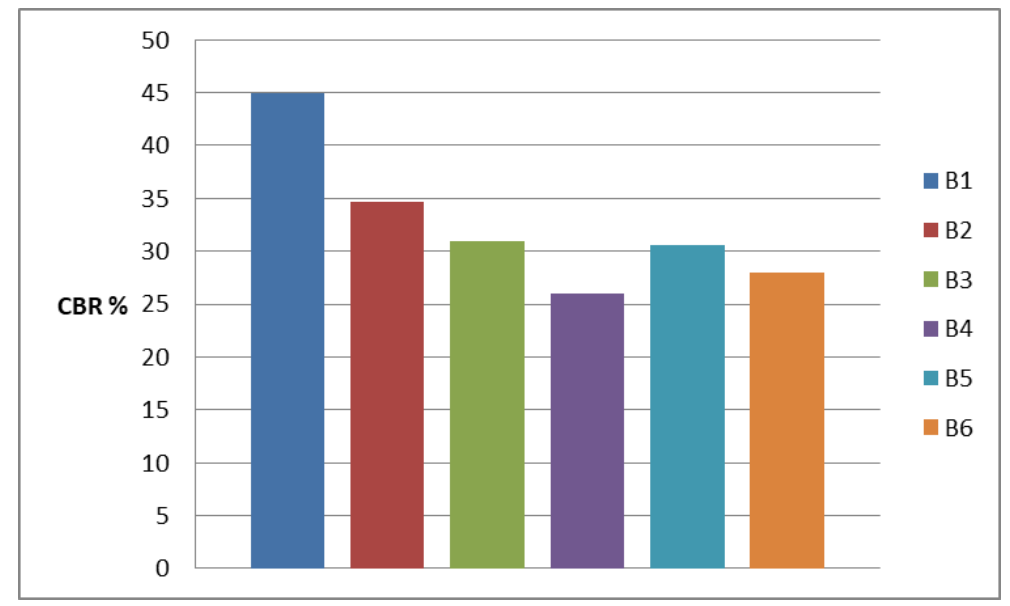

Figure 7: the CBR test results of group (B) blend patterns.

\section{CONCLUSIONS}

Construction process of roads trending to use crushed bricks in pavement layers which is leading to study the feasibility of these materials, this paper studied using of the waste bricks crushed as sand in unbound layers and used with natural sub-base materials in segregated form to produce such study patterns, and its concluded that:

1. The density of CBS is low susceptible to moisture variations as shown in moisture-density relationship test figure (5), it have the higher optimum moisture content due to the lower density and higher water absorption that is make it feasible for using in layer exposed to moisture.

2. The CBR result of CBS alone was less than the limit of subbase course because it is not cohesive non-plastic material and became loose with moisture.

3. The use of crushed bricks as sand with natural aggregate as unbound subbase in segregated form is feasible and agreed with the Iraqi specification requirements because of the CBR of the CBS was improved when mixed with the NA at all the patterns.

4. The best blend is not just with increasing the material which has the high mechanical properties, but in pattern of its distribution within the depth and its position from the top layer. So, the best blend pattern is (A1) which have CBS spread between NA layers and NA at top. This had improved the CBR value compared with control sample of NA, and it gives supporting to the CBS layers.

5. Collecting layers of the same material together doesn't give best enhancement, and the sporadic distribution reduces the effect of low bearing material like in blend patterns.

6. As compared with the control sample of pure CBS, the CBR value is improved when blending $60 \%$ of the CBS with $40 \%$ of NA in patterns B1 and B2 to 5 and 3.7 times respectively, while in blending $40 \%$ of the CBS with $60 \%$ of NA, the CBR is improved to 8 times in blend pattern $A 1$ (compared to the control sample of pure NA is improved about 1.6 times) and increased to 3.3 times in pattern A6. 


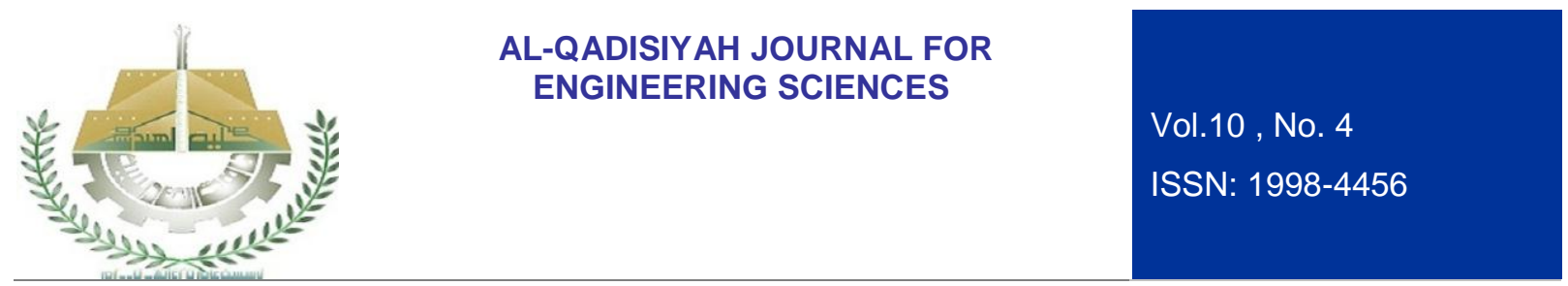

\section{RECOMMENDATIONS}

1. It's recommended to use the Crushed Bricks in road subbase layer construction, when use it as sand in unbound layer in segregated form with natural aggregate and it's recommended to use the blend pattern A1 in mean spreading CBS between NA layers in the series of NA layer above CBS layer (consecutively).

2. It's recommended to use this method of spreading (segregated) instead of mixing the two materials together for easy in the execution.

3. For future studies, it's recommended to use the recycled concrete aggregate instead of the NA or treat the CBS with cement.

\section{REFERENCES}

1. WorkSafe Victoria, "Recycling construction and demolition material", guidance on complying with the occupational health and safety (asbestos) regulations 2003, (2006).

2. Aatheesan, T., Arulrajah, A., Bo, M. W., Vuong, B., and Wilson, J. "Crushed brick blends with crushed rock for pavement systems", Waste Resource Manag., 163(1) (2010), 29-35.

3. A. Choudhary, J. Jha, K. Gill, S.K. Shukla, "Utilization of fly ash and waste recycled product reinforced with plastic wastes as construction materials in flexible pavement", in: Geo-Congress, (2014), pp. 38903902.

4. Wijewardana, A D E De Alwis. S A D Dilini Lakmini and K M L A Udamulla, "The potential of using recycled bricks as a material in sub base applications", M A C D Sri Lanka Association for the Advancement of Science Proceedings of the 71st Annual Sessions, 2015, Part I.

5. Khalaf, F.M.; DeVenny, A.S. "Performance of Brick Aggregate Concrete at High Temperatures", J. Mater., Civ. Eng., 16, (2004), 556-565.

6. Zakaria, M and Rauf, A.F.M. "Behavior of Brick Aggregates in Base and Sub-base Courses Journal", the Institute of Engineers, Bangladesh, Vol. 14. (1986).

7. Poon, C. S., and Chan, D., "Feasible use of recycled concrete aggregates and crushed clay brick as unbound road sub-base", Constr., Build. Mater., 20, (2006), 578-585.

8. Arulrajah, A., Piratheepan, J., Bo, M. W., and Sivakugan, N., "Geotechnical characteristics of recycled crushed brick blends for pavement sub-base applications”, Can., Geotech., J., 49(7), (2012a), 796-811.

9. Arulrajah, A., Piratheepan, J., Aatheesan, T., and Bo, M. W., "Geotechnical properties of recycled crushed brick in pavement applications", journal of materials in civil engineering ( ) asce j ISSN 0899-1561, 23(10), (2011), 1444-1452.

10. A. Arulrajah; J. Piratheepan; M. M. Disfani; and M. W. Bo, M., "Geotechnical and Geo-environmental Properties of Recycled Construction and Demolition Materials in Pavement Subbase Applications", ASCE () 2013 American Society of Civil Engineers, the Journal of Materials in Civil Engineering, Vol. 25, No. 8, ISSN 0899-1561/(2013), pp. 1077-1088.

11. Louis M. A., sultan S., M.SC student Mahdi Z., "Structural Evaluation of Cold Recycling Reclaimed Asphalt Pavement (RAP) Blends", Journal of Engineering and Development, September, ISSN 1813- 7822, Vol. 18, No.5, (2014), P.P 246-263.

12. Arulrajah A., Mahdi M. Disfani, Horpibulsuk S., Suksiripattanapong C. , Prongmanee N., "Physical properties and shear strength responses of recycled construction and demolition materials in unbound pavement base/subbase applications", Construction and Building Materials, 58, (2014), 245-257.

13. Diagne, M., Tinjum, \& Nokkaew, K., "The effects of recycled clay brick content on the engineering properties, weathering durability, and resilient modulus of recycled concrete aggregate", Trans., Geotech., J., 3, (2015), 15-23. 


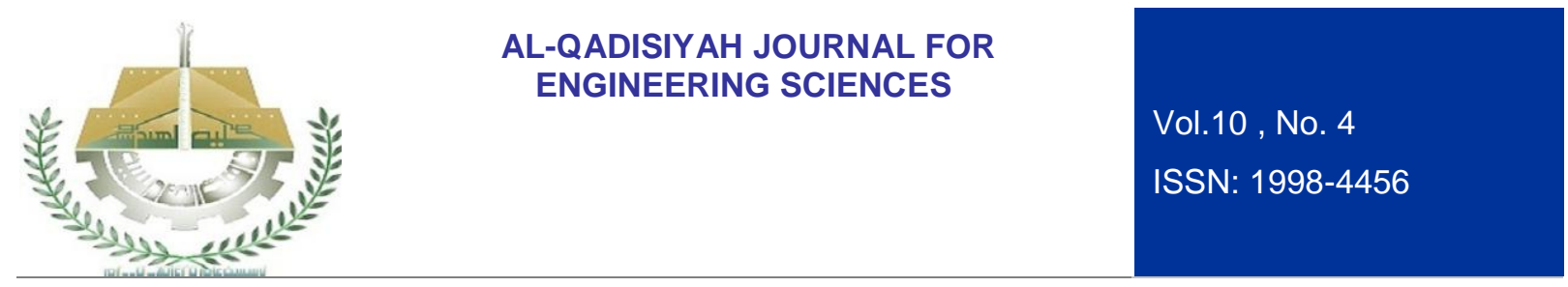

14. Mohammadinia A., Arulrajah A., Horpibulsuk S., Chinkulkijniwat A., "Effect of fly ash on properties of crushed brick and reclaimed asphalt in pavement base/subbase applications",(2017), Journal of Hazardous Materials, Elsevier.

15. ASTM, " standard test method: C136-06: "Standard Test Method for Sieve Analysis of Fine and Coarse Aggregates", American Association of State Highway and Transportation Officials, 444 North Capitol St. N.W., Suite 225, (2006), Washington.

16. ASTM, standard test method: C 4318-05: "Standard Test Methods for Liquid Limit, Plastic Limit, and Plasticity Index of Soils", American Association of State Highway and Transportation Officials, ASTM International, 100 Barr Harbor Drive, PO Box C700, West Conshohocken, (2005), PA 19428-2959, United States.

17. ASTM standard test method: C 128-04: "Standard Test Method for Density, Relative Density (Specific Gravity), and Absorption of Fine Aggregate", American Association of State Highway and Transportation Officials, 444 North Capitol St. N.W., Suite 225, (2004), Washington, DC, United States.

18. ASTM standard test method: D 1557: "Standard Test Methods for Laboratory Compaction Characteristics of Soil Using Modified Effort (56,000 ft-lbf/ft3 (2,700 kn-m/m3))", ASTM International, 100 Barr Harbor Drive, PO Box C700, West Conshohocken, (2003), PA 19428-2959, United States.

19. ASTM, " standard test method: D 1883-05: "Standard Test Method for CBR (California Bearing Ratio) of Laboratory-Compacted Soils", ASTM International, 100 Barr Harbor Drive, PO Box C700, West Conshohocken, (2005), PA 19428-2959, United State.

20. SCRB, State Corporation for Roads and Bridges, "standard specifications for roads and bridges", (2007), design and studies department, Ministry of housing and construction, Republic of Iraq.

$$
\text { 21. سرسم، جلال بشير، عبد المجيد، يوسف عبد وجابر،سعيد عبد العالي، "المو/د الانشائبه"، (1990، الطبعة الاولى ـ دار التقني للنشر بغداد . }
$$

22. Groover, M.P., "Fundamentals of Modern Manufacturing, Material Processes, and Systems", 2nd edition, John Wiley \& Sons, Inc., 2002.

23. Ryan, W., "Properties of Ceramic Raw Material", 2nd edit. Pergamon Press, New York, (1978), pp113. 